\title{
Quem educa queer: a perspetctiva de uma analítica queer aos processos de educação em saúde
}

\author{
Who teaches queer: the prospect of queer theory analysis \\ in the health education process
}

Jose Inácio Jardim Motta ${ }^{1}$

Victória Maria Brant Ribeiro ${ }^{2}$

${ }^{1}$ Escola Nacional de Saúde Pública, Fundação Oswaldo Cruz. R. Leopoldo Bulhões 1480, Manguinhos. 21041-210 Rio de Janeiro RJ.inacio@ensp.fiocruz.br ${ }^{2}$ Núcleo de Tecnologia Educacional para a Saúde Universidade Federal do Rio de Janeiro.

\begin{abstract}
The scope of this essay is to reflect on the possibilities of inclusion of a queer analytical body to the processes of education in the health field. This is because the development of the Unified Health System, with its new set of health practices has revealed challenges that include broadening the knowledge set especially required for revitalization of the notion of subject. Queer theory is needed to understand how identities and in particular gender and sexuality are incorporated, in a social and cultural process, and how, in the micro-social spaces, it can determine educational practices with the power to reinforce the status of the so-called minority sexualities. Queer theory framed in so-called post-critical theories of education is analyzed from the categories of power, resistance, transgression in the context of standardization and subjectivity. It is assumed that processes of education in health, grounded in queer teaching, working in terms of difference and not diversity, proposing processes of deconstruction of binaries such as nature/culture, reason/passion, homosexual/heterosexual, working towards shaping more assertive cultural and social subjects.
\end{abstract}

Key words Queer theory, Gender and sexuality, Health education
Resumo Este ensaio tem o objetivo apresentar uma reflexão sobre as possibilidades de incorporação de um corpo analítico queer aos processos de educação no campo da saúde. Isto porque o desenvolvimento do Sistema Único de Saúde tem revelado desafios que passam pela ampliação de conhecimentos, necessários, principalmente quanto à revitalização da noção de sujeito. Tomamos a perspectiva queer para compreender como as identidades e, em particular, as de gênero e sexualidade, são naturalizadas e essencializadas em um processo social e cultural, e como isso pode determinar, nos micros espaços sociais, práticas educacionais com potência de reforçar a subalternidade das chamadas sexualidades minoritárias. A teoria queer, enquadrada nas chamadas teorias póscríticas da educação, é analisada com base nas categorias: poder, resistência, transgressão em contextos de normalização e subjetivação. Assume-se que processos de educação na saúde, ancorados em uma pedagogia queer, trabalham no plano da diferença e não da diversidade, propondo processos de desconstrução dos binarismos tais como natureza/cultura, razão/paixão, homossexual/ heterossexual, caminhando na conformação de sujeitos sociais e culturais mais transgressores.

Palavras-chave Teoria queer, Gênero e sexualidade, Educação em saúde 


\section{Somos iguais porque somos diferentes ou e se o outro não estivesse por aí?}

Há mais de um século atrás, Fernando Pes$\mathrm{soa}^{1}$, numa linguagem poética e densamente lírica, nos brindava com uma impactante imagem do que seria o sujeito, ou melhor, de como nós percebemos o outro em sua condição de sujeito. Assim, o poeta ao mesmo tempo em que nos instigava, nos colocava zonas de pouco conforto com a seguinte reflexão:

"uma de minhas preocupações constantes é a de compreender como é que outra gente existe, como é que existem almas que não sejam a minha, consciências estranhas à minha consciência que, por ser consciência parece ser a única. Compreendo bem que o homem que está diante de mim, e me fala com palavras iguais às minhas, $\mathrm{e}$ me faz gestos que são como os que eu faço ou poderia fazer, seja de algum modo meu semelhante. O mesmo, porém, me acontece com as gravuras que sonho das ilustrações, com as personagens que vejo dos romances, com as pessoas dramáticas que no palco passam através dos atores que os representam. Ninguém, suponho, admite verdadeiramente a existência real de outra pessoa. Pode conceder que essa pessoa esteja viva, que sinta e pense como ele; mas haverá sempre um elemento anônimo de diferença, uma desvantagem materializada. Os outros não são para nós mais do que paisagem, e, quase sempre, paisagem invisível de rua desconhecida”.

O retrato que Pessoa nos traz, situa bem o contexto em que se instauram as discussões, no âmbito das teorias sociais, dos conceitos e das ideias em torno do sujeito e seus "processos identitários". A questão da identidade vem ganhando um longo e extenso campo de discussões na teoria social. Essa profusão é de tal forma, que Baumam ${ }^{2}$ afirma: "em nossos dias, nenhum outro aspecto da vida contemporânea atraiu a mesma quantidade de atenção de filósofos, cientistas sociais e psicólogos". Para o autor, identidade virou um "prisma" através do qual, outros tópicos da vida contemporânea são localizados, agarrados e examinados.

Sujeitos e identidades passam a fazer parte da produção discursiva de inúmeros enunciados, tanto no campo da saúde, pelos processos de integralidade do cuidado e de humanização da atenção à saúde; tanto na educação, inscritos de diferentes formas principalmente nas teorias críticas e pós-críticas; como na interface da saúde e educação, notadamente por meio da política nacional de educação permanente em saúde.

Por outro lado, o processo de implantação do Sistema Único de Saúde (SUS), compreendi- do como uma política pública qualificada de proteção social vem sendo processado com base em produções discursivas em torno de enunciados que apontam a mudança de modelos de atenção e cuidado em saúde.

O conjunto de princípios e pressupostos que configuram esses enunciados, já foi bem descrito em vários estudos, e podem ser resumidos em dois eixos centrais. Um primeiro, estrutura mudanças nos espaços de organização e gestão do sistema, ancorados fortemente pelas definições de descentralização, regionalização e hierarquização. O segundo aponta mudanças na natureza das práticas de saúde, considerando que as mesmas são conformadas por relações sociais e culturais que se inscrevem em micros espaços sociais, comportando uma necessária analítica de como micro poderes (re)inscrevem a própria possibilidade de mudanças dessas práticas.

Assim, podemos dizer que há um espaço visível nos discursos em torno das mudanças de modelos, traduzido pelo conjunto de normas operacionais do sistema (NOB), pactos de saúde, portarias e protocolos de atenção e cuidado. Porém, há também espaços com graus diferenciados de invisibilidade, espaços inscritos no âmbito das relações entre os sujeitos nos processos de produção em saúde, que nos remetem a processos de subjetivação, ao (re)velamento de identidades e diferenças, à diversidade cultural como um lugar fecundo onde circulam poderes e resistências, e à reificação da noção de sujeito em saúde.

Todavia, ao colocar em destaque a ideia de sujeito, muito dos enunciados das políticas, especialmente as que se originam no campo da saúde, não parecem considerar as diferentes perspectivas de produção de identidades, e como essas identidades estabelecem normas e padrões de relações sociais. Poderíamos pensar ainda que, no quadro das teorias sociais, há um forte processo de instabilidade de tal forma que as velhas identidades, por tanto tempo responsáveis pela estabilização do mundo social, estão em declí nio. Para Hall ${ }^{3}$ a chamada "crise de identidade, é vista como parte de um processo mais amplo de mudança, que está deslocando as estruturas e processos centrais das sociedades modernas e abalando os quadros de referência que davam aos indivíduos uma ancoragem estável no mundo social".

No quadro dos processos identitários, as chamadas identidades minoritárias, etnia, gênero, sexualidade, nos colocam não só o desafio de compreendê-las à luz dos processos de globalização que fragmentam e descentram o sujeito, mas também em sua dimensão cultural e políti- 
ca que as colocam como identidades subalternas referidas a uma identidade hegemônica.

No âmbito da educação, fica cada vez mais claro que os processos de formação precisam avançar não só na garantia da constituição de sujeitos emancipados, categoria tão cara aos teóricos críticos da educação, mas também na compreensão de que os processos culturais conformam sujeitos naturalmente alçados à condição de normal. Logo, se existem sujeitos produzidos como normais, há também sujeitos produzidos como anormais, usualmente colocados na condição de inferioridade ou subalternidade. Isso aponta desafios aos processos de educação no âmbito da saúde, que ao não abandonarem uma perspectiva "emancipatória" em seus processos, deverão inscrever os novos aportes advindos dos teóricos pós-críticos. Estes, ao darem ênfase ao conceito de discurso em detrimento do de ideologia, indicam novas estratégias pedagógicas que valorizem categorias como identidade, subjetividade, multiculturalismo, dentre outras, nos processos educacionais. Isso implica em compreender os processos e as condições de descentramento dos sujeitos de uma identidade fixa e centrada para um sujeito que habita o lugar das fronteiras. Todavia, não é possível abandonar a categoria ideologia, todos sabem que não há discurso desprovido de ideologia. Na verdade, ocorre sim um deslocamento em sua centralidade. No fundo, o que está em jogo é o descentramento da categoria poder.

Na perspectiva das teorias pós-críticas da educação, tomaremos como referência os teóricos queer, compreendendo serem estes os que melhor circunscrevem uma analítica da normalidade referida aos marcos que constituem padrões culturais tidos como normais, possibilitando também, entender o papel dos processos de educação na saúde, na produção e no reforço a esses padrões, bem como, suas estratégias de desconstrução. Essa opção aponta uma tentativa de se pensar as formas de práticas e de usos dos saberes e poderes na nossa sociedade atual e como essas relações vão configurando modos de subjetivação. Para nós, isto significa pensar esses modos de subjetivação como históricos, resultados de discursos e que se afastam de uma ideia de sujeito racional, ideal e coerente para apostar na força da construção e transformação, num processo sempre aberto e repleto de possibilidades.

A constituição de sujeitos subalternos marca profundamente um território de diferenças. Estas, por sua vez, marcarão um campo de vivências de desigualdades e injustiças que irão caracterizar grupos socialmente marcados como inferi- ores. Para Miskolci " "as minorias étnico-raciais, de gênero e sexuais explicitam maneiras tão diversas de vivenciar a diferença que tornam patente o fato de que, ainda que sejam mais ou menos relacionadas, cada diferença denota uma forma particular de opressão".

Ao se referir a esse processo opressivo, quando relacionado às questões sexuais, Furlani ${ }^{5}$ aponta que:

"a diferença cultural dependerá de inúmeros processos de exclusão, de vigilância de fronteiras, de estratégias de divisão que, em última análise, definem hierarquias, escalas valorativas, sistemas de categorização".

Compreender como as diferentes identidades se constituem em processos de diferenças, e como essas diferenças acenam contextos de normas, regras, opressões e exclusões, deveria ser prioridade todas as vezes que uma política social, notadamente nas áreas de educação e saúde, fosse enunciada e implementada.

Esse trabalho visa explorar as possibilidades de uma analítica queer aos processos de educação na saúde, considerando que são práticas sociais que interferem diretamente nos processos de subjetivação, contribuindo para os sujeitos se tornarem o que são, ou seja, sujeitos de saberes que se constituem em relações de poder e com potência de autogoverno.

\section{Estranhando a estranheza ou onde anda o queer?}

No inicio dos anos 80, Foucault ${ }^{6}$, em uma entrevista à revista canadense Body Politic, descentra o foco das análises sobre sexualidade do conjunto de regras que norteiam condutas sociais e exercícios de prazer, para olhar a sexualidade como uma "arte de viver", e aponta:

“... a sexualidade faz parte de nossa conduta. Ela faz parte da liberdade em nosso usufruto deste mundo. A sexualidade é algo que nós mesmos criamos - ela é nossa própria criação, ou melhor, ela não é a descoberta de um aspecto secreto de nosso desejo. Nós devemos compreender que, com nossos desejos, através deles, se instauram novas formas de relações, novas formas de amor e novas formas de criação. O sexo não é uma fatalidade; ele é uma possibilidade de aceder a uma vida criativa”.

Essa perspectiva apontada por Foucault, com a qual a sexualidade é vista como algo a ser construído desde um processo criativo e inscrito em um exercício de "poiesis humana", é tencionado pela dura realidade do cotidiano. Eribon ${ }^{7}$ chama de "choque da injuria" o processo de exclusão que 
crianças e adolescentes vivem quando são identificados (por diferentes razões, não necessariamente de identidade sexual), como diferentes da ordem sexual hegemônica. Para o autor, xingamentos como "viado/sapata nojento(a)" não são simples palavras lançadas a esmo. "São agressões verbais que marcam a consciência. São traumatismos sentidos de modo mais ou menos violento no instante, mas que se inscrevem na memória e no corpo". E uma das consequências da injúria é moldar a relação com os outros e com o mundo. E, por conseguinte, moldar a personalidade, a subjetividade, o próprio ser de um indivíduo.

Queer pode ser traduzido como estranho, excêntrico, raro, extraordinário, ridículo. Esse termo passa a ser utilizado por um grupo de teóricos que pensam as questões de gênero e sexualidade com base em uma perspectiva pós-crítica. Para Miskolci ${ }^{4}$, a escolha desse termo para se autodenominarem, ou seja, um xingamento que denota perversão e desvio destaca um "compromisso em desenvolver uma analítica da normalização focada na sexualidade". Dessa forma, passam a refletir como a sexualidade é moldada e atravessada por discursos de normalização e, trazendo para o campo da investigação, "a dinâmica da sexualidade e do desejo na organização das relações sociais".

Para Pereira ${ }^{8}$, a teoria queer apresenta um campo semântico permeado de provocações, composto por vocábulos tais como: "reconversão, deslocamento, desnaturalização, subversão, performance, paródia”. O autor enfatiza que essas expressões são "tropos que indicam movimento e transformação”. Dessa forma a própria opção pelo queer tem um caráter político e anunciador de processos que tendem a subverter e transformar o instituído, naturalizado, como o correto e o normal. Essa perspectiva explicita um compromisso desses teóricos em produzir uma analítica que demonstre os processos que criam sujeitos normais e adaptados por meio da construção de sujeitos ilegítimos, rotulados como anormais e alocados na margem do social ${ }^{4,9}$.

Em termos teóricos e metodológicos, os estudos queer, surgiram do encontro de uma corrente dos Estudos Culturais americanos, com o pós-estruturalismo francês. Os teóricos queer encontram, nas obras de Foucault, a ideia de que a sexualidade é um dispositivo histórico do poder, que se baseou na inserção do sexo em sistemas de utilidade e regulação social.

Para Silva ${ }^{10}$, o objetivo da teoria queer é o de "complicar a questão da identidade e, indiretamente, também a questão da identidade cultural e social". A política queer consiste assim em perturbar os binários de gênero e brincar, como aponta Pereira ${ }^{8}$, com as menções feitas de gênero, que devem ser vistas desde um olhar sobre o sexo como uma produção discursiva.

Nesse sentido, os teóricos queer serão influenciados por uma vertente dos estudos culturais americanos, notadamente alguns estudos feministas, dentre eles destacam-se os escritos de Judith Butler ${ }^{11}$. Essa autora provoca uma tensão permanente sobre o binarismo de gêneros apontando que:

"A hipótese de um sistema binário dos gêneros encerra implicitamente a crença numa relação mimética entre gênero e sexo, na qual o gênero reflete o sexo ou é por ele restrito. Quando o status construído do gênero é teorizado como radicalmente independente do sexo, o próprio gênero se torna um artifício flutuante, com a consequência de que homem e masculino podem, com igual facilidade, significar tanto um corpo feminino como um masculino, e mulher e feminino, tanto um corpo masculino como um feminino"11.

Assim, os estudos de Butler apontam que o gênero não acontece quando nascemos, mas sim por uma sequência de atos repetidos que enrijece de tal forma, que toma a aparência de algo que esteve ali o tempo todo ${ }^{12}$.

Dessa forma, vários autores vão destacar que, tal como os estudos feministas, a teoria queer compreende que a identidade sexual não é definida simplesmente pela biologia, mas também pela dependência da significação que lhe é dada, razão pela qual passa a ser uma construção social e histórica ${ }^{10,12}$.

A obra de Butler tem se preocupado, em grande parte, com a análise e a consequente desestabilização da categoria sujeito, em um processo que ela chama de "uma genealogia crítica das ontologias de gênero". Dessa forma, enquanto os estudos de gênero, os estudos gays e lésbicos podem ter tomado a existência do sujeito "feminino" do sujeito gay ou lésbico, a perspectiva queer, tal qual Butler aponta, empreende uma investigação e uma desconstrução dessas categorias, afirmando a indeterminação e a instabilidade de todas as identidades sexuadas e "generificadas". Devemos ressaltar que Butler em suas teorizações da heterossexualidade, recorria a Freud, vendo-a como uma estrutura de identidade "melancólica”, na medida em que está baseada numa "perda” ou rejeição primária - socialmente imposta - do desejo homossexual. Vários autores vão afirmar que a "heterossexualidade melancólica”, é uma das contribuições mais importantes de Butler para a teoria queer ${ }^{12}$.

Aprofundando o campo de análise em torno da teoria queer, Santos ${ }^{13}$ aponta alguns de seus 
elementos fundamentais: as identidades são sempre múltiplas e compostas por um número infinito de "componentes de identidade"; qualquer identidade construída é arbitrária, instável e excludente, uma vez que implica em silenciar outras experiências de vida; reconhecer seu significado permanentemente aberto, fluído e passível de contestação, a construção de uma cultura em que a diversidade é acolhida. Sendo assim, os estudos queer, acabam por ultrapassar as questões referidas à sexualidade, em especial os diferentes dispositivos advindos do heterossexismo, se inscrevendo em um campo maior de análise e compreensão dos mecanismos de poder, resistência e liberdade relacionadas à produção de identidades culturais.

Reforçando essa perspectiva, Miskolci ${ }^{14}$ aponta que: "O queer busca tornar visíveis as injustiças e as violências implicadas na disseminação e na demanda do cumprimento das normas e das conversões culturais, violências e injustiças envolvidas tanto na criação dos 'normais' quanto dos 'anormais"'.

No campo da educação o mesmo autor ressalta que os estudos queer nos ajudam a compreender e refletir sobre:

“... os laços profundos entre educação e normalização social, entre a escola e os interesses biopolíticos, entre o sistema educacional e a imposição de modelos de como ser homem ou mulher, masculino ou feminino, hétero ou homossexual. Refletir para questionar e propor algo distinto, não normalizador ou compulsório, um educar fincado não em modelos e conteúdos que o precedem, mas, antes na experiência mesma do aprender"14.

De igual forma, a saúde como uma prática de normalização da vida alheia, de construção de regras e de condutas sobre o que deve ou não ou como se deve ou não ser, é atravessada pelos interesses biopolíticos, construindo discursos sociais em torno do que pode ser aceitável socialmente em contraposição ao que não pode ser aceito. Logo, o campo das relações entre saúde e educação se torna território fecundo para uma analítica queer e a proposição de estratégias pedagógicas que considerem sua perspectiva teórica.

\section{Sou normal porque sou heterossexual ou sou heterossexual porque sou normal? Um pouco de história ou de como surge a heteronormatividade}

Uma recomposição histórica da ideia de identidade referida às questões de gênero e em especial às sexualidades não é uma tarefa fácil. Ao mesmo tempo em que as discussões sobre a catego- ria identidade se tornaram mais complexas, as referências históricas sobre a sexualidade e, em especial, a construção das homossexualidades e dos processos homofóbicos devem sinalizar conquistas sociais, mas, sobretudo, devem expressar graus progressivos de subjugação a uma norma social e culturalmente produzida desde diferentes discursos ao longo do tempo.

Foucault nos aponta que a ideia do sexo como algo que na sociedade pode ser visto como pecaminoso, perverso, puro e silenciado, é uma invenção da história moderna e, em particular, das sociedades ocidentais da era vitoriana. Sobre esse momento o autor assim se expressa:

"Um rápido crepúsculo se teria seguido à luz meridiana, até as noites monótonas da burguesia vitoriana. A sexualidade é, então, cuidadosamente encerrada. Muda-se para dentro de casa. A família conjugal a confisca. E absorve-a, inteiramente, na seriedade da função de reproduzir. Em torno do sexo, se cala. O casal, legítimo e procriador, dita a lei. Impõe-se como modelo, faz reinar a norma, detém a verdade, guarda o direito de falar, reservando-se o princípio do segredo"15.

Se, nesse momento, a função sexual é a reprodução, o casal heterossexual monogâmico passa a ser o espelho. Outras formas de sexualidade começam a ser atravessadas por um conjunto de dispositivos que em geral tem a clara função de interdição e banimento. Nesse sentido, o mesmo autor nos indica a possibilidade de podermos revelar os princípios que irão reger esse conjunto de dispositivos, ou seja, a necessidade de:

“... buscar as instâncias de produção discursiva (que, evidentemente, também organizam silêncios), de produção de poder (que algumas vezes têm função de interditar), das produções de saberes (as quais, frequentemente, fazem circular erros ou desconhecimentos sistemáticos)"15.

Se o exercício da sexualidade ganha contornos de interdição e silêncios, as homossexualidades e os sujeitos homossexuais, de igual forma, "são invenções do século XIX" . Louro ${ }^{9}$ destaca que, "relações amorosas e sexuais entre pessoas do mesmo sexo eram consideradas como sodomia" uma atividade percebida como indesejável, mas que todas as pessoas poderiam sucumbir. Entretanto, a partir dessa época, tal prática marca com profundidade os sujeitos de tal forma que, uma vez "categorizado e nomeado como desvio da norma, seu destino só poderia ser o segredo ou a segregação".

As formas como a homossexualidade vai se constituindo em zonas de interdição, gerando saberes que a constrói como algo indesejável, perverso, doente, se confunde com o desenvolvi- 
mento de diferentes manifestações de homofobia. Esta consiste em designar o outro "como contrário, inferior ou anormal", posicionandoo à distância, "fora do universo comum dos humanos". Assim, é comparada a outras manifestações arbitrárias tais como a xenofobia, o racismo ou o antissemitismo ${ }^{16}$.

Portanto, é em torno do sexo, cor de pele ou função religiosa que se instaura um "dispositivo intelectual e político de discriminação". No que se refere à discriminação de sexo, Borrilo ${ }^{16}$ assim denuncia:

"O sistema a partir do qual uma sociedade organiza um tratamento segregacionista segundo a orientação sexual pode ser designado sobre o termo geral de "heterossexismo". Esse sistema e a homofobia - compreendida como a consequência psicológica de uma representação social que, pelo fato de outorgar o monopólio da normalidade à heterossexualidade, fomenta o desdém em relação àquelas ou àqueles que se afastam do modelo de referência - constituem as duas faces da mesma intolerância e, por conseguinte, merecem ser denunciadas com o mesmo vigor utilizado contra o racismo ou o antissemitismo".

Pode-se dizer, sem grandes erros, que o mundo greco-romano se relacionava com a homossexualidade em ambientes bem mais descontraídos do que o conjunto de dispositivos disciplinares usados pela era moderna. De igual forma, é possível perceber que os diversos padrões de homofobia com que a sociedade atual convive são fortemente influenciados pelas três religiões monoteístas, o cristianismo, o judaísmo e o islamismo.

Para o pensamento pagão, a sexualidade entre pessoas do mesmo sexo era considerada "um elemento constitutivo, até mesmo indispensável da vida do indivíduo". Esse processo é, em um primeiro momento, atravessado por princípios canônicos, que levam ao binarismo masculino/ feminino como uma divisão primordial, compreendida como originária ou essencial, e quase sempre relacionada ao corpo $^{9,16}$.

Da mesma forma, a ciência reforça enunciados de interdição e anormalidade, reforçando a verdade não como um ideal divino ou uma ordem moral, mas sim ancorado em princípios do método científico. Sobre isso as palavras de Borrilo ${ }^{16}$ são contundentes:

"Começando por estar a serviço da medicina e, em seguida, das ciências sociais, os prazeres homossexuais tornam-se o objeto privilegiado de uma nova tentativa de normalização dos indivíduos e da subjugação das consciências. A antiga hostilidade religiosa contra os sodomitas encontra nova vitalidade em um discurso que, revesti- do de linguagem científica, torna legítima a inferiorização e, às vezes, até mesmo o extermínio dos indivíduos considerados, daí em diante, não mais pecadores, contrários à ordem divina, mas como perversos e perigosos para a ordem sanitária”.

Assim, a saúde passa a ser um território fecundo de produção de discursos normalizadores, contribuindo para marcar um campo de diferenças culturais. Uma diferença é marcada profundamente por uma identidade, ou seja, a identidade fornece as condições de existência da diferença. A diferença é marcada pela exclusão ${ }^{17}$.

A partir dos anos 70 do século XX, constróise aos poucos a ideia de uma comunidade homossexual, com movimentos cada vez mais organizados em torno da busca e da reafirmação de direitos sociais. Ao mesmo tempo em que se avança em muitos países do hemisfério norte, a inscrição desses direitos, como base jurídico-legal, denuncia a precária linha entre normatividade e exclusão, silêncio e reafirmação de uma história de perseguições e dores. Afirma-se discursiva e praticamente uma identidade homossexual.

Por essa época, surgem os chamados "novos movimentos sociais". Novos porque "trouxeram ao espaço público demandas que iam além das de redistribuição econômica”. Esses novos movimentos, em especial o de negros, o feminismo e o dos homossexuais, irão lutar por direitos civis, denunciando um campo de desigualdades sociais que ultrapassa as desigualdades referidas à base econômica ${ }^{14}$.

No que se refere aos movimentos homossexuais, estes foram impactados em meados dos anos 80 pela epidemia de HIV. Com isso, se restitui um discurso conservador, tributando a esse grupo populacional a culpa e o castigo "para aqueles que não seguiam a ordem sexual tradicional". Nesse sentido, a epidemia é tanto um fator biológico como uma construção social ${ }^{14}$.

É nesse contexto que surgem os teóricos queer, expressando uma luta em que, segundo Miskol$\mathrm{ci}^{14}$, em sua perspectiva política, ao invés de uma simples defesa da homossexualidade tais quais reivindicavam os movimentos LGBTT, se preocupavam na crítica aos regimes de normalização, reafirmando, não uma perspectiva de diversidade, mas sim de diferença. Ao mesmo tempo faziam um contraponto às concepções de poder centradas na função repressora, para denunciar suas formas de disciplinamento e controle.

Com isso, trazem a tona termos como heterossexismo, heterossexualidade compulsória e heteronormatividade. Podemos compreender que o heterossexismo é a presunção de que o modelo heterossexual é natural, ou seja, a concepção de 
que todo mundo é, ou deveria ser, heterossexual. A heterossexualidade compulsória é entendida como a imposição como modelo das relações amorosas e sexuais entre pessoas do sexo oposto. Contudo, o conceito central para os teóricos queer é a heteronormatividade. Esse conceito vai expressar as expectativas, as demandas e as obrigações sociais que derivam do pressuposto da heterossexualidade como normal e, portanto, fundamento da sociedade. Pode ser assim compreendido:

"aquelas instituições, estruturas de compreensão e orientações práticas que não apenas fazem com que a heterossexualidade pareça coerente - ou seja, organizada como sexualidade mas que também seja privilegiada. Sua coerência é sempre provisional e seu privilégio pode adotar várias formas (que às vezes são contraditórias): passa despercebida como linguagem básica sobre aspectos sociais e pessoais; é percebida como um estado natural; também se projeta como um objetivo ideal ou moral"4.

Como um conjunto de prescrições que fundamenta processos sociais de regulação e controle, a heteronormatividade marca até mesmo aqueles que não se relacionam com pessoas do sexo oposto. Assim, a heteronormatividade não se refere apenas aos sujeitos legítimos e normalizados, mas é uma denominação contemporânea para o dispositivo histórico da sexualidade que evidencia seu objetivo: formar a todos para serem heterossexuais ou organizarem suas vidas com base no modelo supostamente coerente, superior e "natural" da heterossexualidade.

\section{O signo da heteronormatividade e a educação ou quem educa queer?}

A educação tem sido na humanidade o território das disciplinaridades, de normas e regras, que discursivamente anunciam a construção do homem cidadão e relacional, do homem civilizado, preparado para viver em comunidade, conviver com outros homens desconhecidos por meio de uma ordem social.

Ainda permanece como um grande desafio da educação, o de repensar o que é educar, como educar e para que educar. Se partimos de um olhar não normalizador, educar seria uma atividade dialógica em que as experiências até hoje "invisibilizadas, não reconhecidas ou, mais comumente, violentadas", passar a ser incorporadas no cotidiano dos processos educacionais, modificando a hierarquia de quem educa e de quem é educado. Significaria para a educação, deixar de ser "um dos braços de normalização biopolítica para o Estado" e passar a ser "um veiculo social" de desconstrução de uma ordem histórica de desigualdade e injustiças ${ }^{14}$.

A teoria queer no âmbito da educação tem sido alocada no interior das chamadas teorias pós-críticas. Estas, de acordo com Silva ${ }^{10}$ afirmam o papel da educação e do currículo como estruturas de poder; entretanto, o poder não é algo centrado e sim "espalhado por toda a rede social”. Para o autor, "nas teorias pós-críticas o conhecimento não é exterior ao poder, o conhecimento se opõe ao poder. $\mathrm{O}$ conhecimento não é aquilo que põe em xeque o poder: o conhecimento é parte inerente do poder" ${ }^{10}$.

A educação como um campo que vive de projetos e de programas, de objetivos e planos de ações, de conhecimentos disciplinadores, vai ser tensionada pelos queer, ao trazerem para esse espaço normalizador, ideias de poder e resistência, liberdade e transgressão. Colocam em foco, temas como abjeção, subjetivação e silenciamento, tencionando a tradicional perspectiva do multiculturalismo com seu ideal de tolerância na diversidade. Com isso, assumem um enfoque mais centrado na diferença do que na diversidade. Para Miskolci ${ }^{14}$, há uma substancial diferença em se trabalhar na lógica da diversidade em lugar da lógica da diferença, e assim se expressa:

"Se a diversidade apela para uma concepção horizontalizada de relações, em que se afasta o conflito e a divergência em nome da conciliação, lidar com a diferença é incomensurável. Mas as diferenças têm o potencial de modificar as hierarquias, colocar em diálogo os subalternizados com o hegemônico, de forma, quiçá, a mudar a ordem hegemônica, a mudar a nós mesmos".

Tomar a diferença é assumir que ela é marcada por "representações simbólicas que atribuem significado às relações sociais". Todavia é também assumi-las enquanto inscritas em jogos de poder que tendem a conformar binarismos tais como natureza/cultura, corpo/mente, paixão/razão. Uma perspectiva queer na educação não só vai assumir a diferença, mas, de igual forma, vai colocar em questão a naturalização desses binarismos ${ }^{17}$.

O que se coloca aqui, considerando o conceito de heteronormatividade anteriormente apresentado, é a possibilidade de a educação operar a desconstrução do binarismo referido à oposição hetero/homossexual. Para Louro, uma pedagogia e um currículo queer, "estariam voltados para um processo de produção de diferenças e trabalhariam, centralmente, com a instabilidade e a precariedade de todas as identidades". Nessa perspectiva, volta-se para a presença do outro e como esse outro pode representar e constituir a dife- 
rença. Ao colocar em discussão as formas como o outro é constituído, leva a questionar as estreitas relações do eu com o outro. A diferença deixa de estar ausente para estar presente, fazendo sentido, assombrando e desestabilizando o sujeito ${ }^{18}$.

Ao se opor à conformação de um mundo binário, os processos pedagógicos inspirados no queer assumem uma conformação de resistência e liberdade. Resistir seria recusar a admitir o que nos tornamos. Seria a produção de "novas formas de subjetividades, negar a imposição da disciplinarização, da normalização, da dominação". Pressupõe uma ação política de ruptura dos binarismos e de resistência, na medida em que a tomamos como "ponto de partida para pensar condições de liberdade". Liberdade como uma "condição ontológica da ética”. Nesse sentido, há uma total associação entre ética e liberdade em Focault. Seu pensamento revela que a ética é, pois, a prática da liberdade, a prática refletida da liberdade ${ }^{19,20}$.

A ideia de transgressão pode ser compreendida como uma experiência limite. O lugar e o ponto de ruptura, capaz de produzir deslocamentos e rupturas das condições que estabeleceram normas e padrões de uma dada vida social. Logo, a transgressão afirma o limite como algo ilimitado, em que "os limites só aparecem no instante em que são transgredidos". Assim, pode-se afirmar que a transgressão é o "ultrapassamento dos limites históricos de uma determinada experiência"21.

Um processo educacional estruturado com base em uma analítica queer deve considerar sempre a perspectiva da superação desses limites históricos. Superar significa romper normas, mas também que novas normas serão reinstaladas, $o$ que, no tempo, irá requerer novos limites de superação. Logo, tomar uma perspectiva queer, é assumir o caráter sempre provisório das rupturas e o caráter permanente da transgressão.

Processo de ruptura se inscreve sobre processos de produção de normas. Aqui teremos um enfrentamento e uma tensão permanente entre os atos de saúde e educação em uma sociedade constituída na base da norma. Foucault ${ }^{22}$ destaca o papel da medicina nesse cenário:

"Tornamo-nos uma sociedade articulada, por essência, com a norma. Isso implica um sistema de vigilância, de controle, completamente diferente: uma visibilidade incessante, uma classificação permanente dos indivíduos, uma hierarquização, uma qualificação, o estabelecimento de limites e de diagnósticos. A norma se torna critério de divisão dos indivíduos. Dado o fato de estar sendo constituída uma sociedade da norma, a medicina, como a ciência acima de tudo do normal e do patológico, será a ciência rainha”.
Pensar então em uma pedagogia ou em um currículo queer, é ultrapassar os limites aos quais algo pode ou deve ser tolerado. Há um deslocamento entre perguntar o "como pensar" para "o que torna algo pensável”. É estar sempre pensando o impensável, "um currículo que força os limites das epistemes: um currículo que não se limita a questionar o conhecimento como socialmente construído, mas se aventura a explorar aquilo que ainda não foi conhecido" ${ }^{10}$.

Os processos de formação e requalificação no campo da saúde vivem a tensão entre o lugar da ruptura em direção a novos arranjos organizacionais, as novas práticas de saúde e as novas interações entre campos de conhecimentos diversos, com sua tradicional ênfase em processos normalizadores e disciplinadores da vida humana.

Nesse sentindo, ao tomarmos as ideias de regras e normas, tradicionalmente presentes nos discursos da saúde, estamos na verdade descortinando espaços de produção de poderes. Poder, como dizia Foucault, que se exerce cada vez mais em um domínio que não é o da lei e sim o da norma, exercido por meio de duas modalidades fundamentais, a disciplina e o biopoder ${ }^{22,23}$.

Por outro lado, os espaços relacionais na produção de atos em saúde, permeados por processos de subjetivação, vão sendo afetados pelos mesmos mecanismos inerentes aos processos normalizadores vinculados pelas práticas discursivas no âmbito da saúde. Dessa forma, há um aparente paradoxo entre a produção discursiva vinculada em um conjunto de políticas de saúde, em especial as que informam sobre modelos de cuidado em saúde, de educação no campo da saúde e atenção integral às populações denominadas de "minorias", e a compreensão de quem são esses sujeitos relacionais e os mecanismos pelos quais eles se tornaram o que são.

É sobre esse cenário que pensar uma analítica queer aos processos de educação no campo da saúde encontra um campo fecundo de possibilidades. Não apenas como um espaço de revelamento dos caminhos pelos quais a sexualidade é vivida com base em regras e normas, mas, principalmente, pela provocação e pelo convite à conformação de sujeitos sociais e culturais mais resistentes às normas e mais transgressores em seu modo de estar no mundo. Sujeitos capazes de resistir a conhecimentos normalizadores e classificadores do outro. Sujeitos capazes de práticas de liberdade na direção de novas possibilidades de acolhimento e alteridade a tudo o que significa vida humana.

As escolas e os serviços de saúde têm sido modos de controle e regulação resistentes às ações coletivas, principalmente em seus micros espaços 
políticos, especialmente quando propõem novos valores que se colocam como "contravalores" na história ocidental. No contexto da educação, supõe-se que o corpo normal personifica um significado estável. O corpo normal é construído social e culturalmente com base em um conjunto de produções discursivas, em particular as inerentes à medicina e à justiça. Essas produções discursivas, por sua vez, encontram na escola o espaço central para a sua disseminação e a formulação de estratégias para sua manutenção ${ }^{24,25}$.

Os processos de formação na saúde são usualmente marcados por fortes conteúdos normalizadores e disciplinadores da vida humana. Pensar uma perspectiva queer é assumir a educação como um espaço social de desconstrução de uma ordem histórica de desigualdades e injustiças. Miskolci ${ }^{14}$ argumenta que o "primeiro passo" seria "identificar e desconstruir" os pressupostos de neutralidade sob os quais por tanto tempo se assentaram os processos educativos na saúde.

Já os processos de requalificação em saúde, em particular a educação permanente em saúde, por sua natureza processual, de instabilidade e incompletude do conhecimento, se tornam um território fecundo para assumir no plano pedagógico uma perspectiva queer. A possibilidade de um olhar sempre crítico para as relações entre sujeitos mediados pelo trabalho coloca, em permanente tensão, as representações culturais com as quais vivemos e aprendemos. Isso nos leva a inserir o ruído, a dúvida sobre coisas que antes eram vistas como "naturais ou indiscutíveis". É esse o lugar que habita o queer.

A educação permanente como uma das estratégias de mudanças nas práticas de saúde, descortina o espaço relacional na produção de conhecimentos a partir da dinâmica do trabalho. Isso significa dizer, que ela se constitui em uma prática educativa que revela conflitos e diferenças, orientando-se para o exercício da democracia participativa. Ao apontar a diferença entre sujeitos nos ambientes de trabalho como um espaço fecundo de produção de novos conhecimentos, uma perspectiva queer, ao valorizar a tensão que constitui essa diferença, produz uma ausculta aos discursos dispersos e fragmentados em pequenos relatos, "nos quais se fazem ouvir as vozes da diferença”. Nesse sentido, trata-se de um compromisso filosófico e político com as minorias, e ideológico com a alteridade ${ }^{26}$.

A arte de educar habita o território da construção afetiva relacional do conhecimento. Fur$\operatorname{lani}^{27}$ alerta que:

“é imprescindível, a qualquer processo de educação e de formação de educadores, duvidar da norma, questionar as hegemonias, por em questão a moralidade conservadora, explicitar os mecanismos históricos e políticos que marcam os diferentes como significativamente indesejáveis".

Dessa trajetória, podemos compreender, tomando emprestadas as palavras de Louro ${ }^{18}$, que o queer "é um jeito de pensar e ser que não aspira o centro e nem o quer como referência: um jeito de pensar e ser que desafia as normas regulatórias da sociedade, que assume o desconforto da ambiguidade, do entre lugares".

\section{Considerações finais}

De tudo que foi refletido, e entendemos ser essa uma reflexão inicial, é preciso compreender que os processos educacionais no campo da saúde se articulados a partir de uma "educação queer", reconhecem não só a importância histórica dos processos de subjetivação, mas se assumem como dispositivos que reforçam ou modificam esses processos. Toda subjetividade se constitui em uma forma de ser sujeito, que ao longo da história se modifica, mostrando que estamos diante de algo em constante construção, em permanente modificação, e que são os "processos de subjetivação". São esses processos que mantêm vivas as possibilidades de resistência e transgressão. A saúde deve ir além de uma prática que estabelece regras de como melhor andar a vida. A saúde, ao assumir a necessidade de novas práticas na direção da produção de sujeitos com autonomia, respeitando seus processos de subjetivação, encontra na educação, e a nosso ver na educação com base em uma perspectiva queer, uma importante estratégia pedagógica. Devemos lembrar que a demanda queer é a do reconhecimento sem assimilação, é o desejo que resiste às imposições culturais dominantes. Miskolci nos lembra que em uma educação queer, ao invés de ensinar e reproduzir a experiência da abjeção, o processo de aprendizado pode ser de ressignificação do estranho, do anormal como veículo de mudança social e abertura para o futuro ${ }^{14,28}$.

Ainda que a literatura brasileira não aponte experiências queer aplicadas aos processos de educação no campo da saúde, acreditamos que essa perspectiva possa ser uma das estratégias pedagógicas de escolha e com potência de desestabilizar os currículos de formação em saúde, tão permeados pelos signos da norma e do disciplinamento, considerando que ainda vivemos tempos que muito se fala de mudanças na graduação.

Da mesma forma, cremos na possibilidade real de que os processos de educação permanente, tão 
amplamente discutidos hoje no âmbito dos serviços de saúde, possam utilizar o potencial desestabilizador e de desconstrução da teoria queer, como um mote para a produção de novos conhecimentos e novas subjetividades que de fato possibilitem novas práticas de saúde contribuindo para a construção de uma sociedade mais equânime.

\section{Referências}

1. Pessoa F. O Livro do Desassossego. São Paulo: Companhia das Letras; 1999.

2. Bauman Z. A Sociedade Individualizada: vidas contadas e histórias vividas. Rio de Janeiro: Zahar Editoras; 2008.

3. Hall S. A Identidade Cultural na Pós-Modernidade. Rio de Janeiro: DP\&A Editora; 2006.

4. Miskolci R. A Teoria Queer e a Sociologia: o desafio de uma analítica da normalização. Sociologias 2009; 11(21):150-182.

5. Furlani J. Sexo, Sexualidade e Gêneros: monstruosidades no currículo de educação sexual. Educação em Revista 2007; (46):269-285.

6. Foucault M. Sex, Power and the Politics of Identity. The Advogate 1984; 400:22-30.

7. Eribon D. Reflexões sobre a Questão Gay. Rio de Janeiro: Companhia de Freud; 2008.

8. Pereira PPG. Corpo, Sexo e Subversões: reflexões sobre duas teorias queer. Interface Comun Saúde Educ 2008; 12(26):499-512.

9. Louro GL. Teoria Queer - Uma Política Pós-identitária para a Educação. Rev. Estudos Feministas 2001; 9(2):541-553.

10. Silva TT. Documento de Identidade: uma introdução às teorias do currículo. Belo Horizonte: Autêntica Editora; 2007.

11. Butler J. Problemas de Gênero: feminismo e subversão da identidade. Rio de Janeiro: Civilização Brasileira; 2008.

12. Salih S. Judith Buttler e a Teoria Queer. Belo Horizonte: Autêntica Editora; 2012.

13. Santos AC. Heteroqueers contra a Heteronormatividade: notas para uma teoria queer inclusiva. [acessado 2010 jul 26]. Disponível em: http://www.ces.uc.pt/ myces.../223_oficina_do_ces_239_nov/2005.pdf

14. Miskolci R. Teoria Queer: um aprendizado pelas diferenças. Belo Horizonte: Autêntica Editora; 2012.

15. Foucault M. História da Sexualidade I: A Vontade de Saber. Rio de Janeiro: Editora Graal; 2010.

16. Borrilo D. Homofobia: História e Crítica de um Preconceito. Belo Horizonte: Autêntica Editora; 2010.

\section{Colaboradores}

JIJ Motta e VMB Ribeiro participaram igualmente de todas as etapas de elaboração do artigo.
17. Woodward K. Identidade e Diferença: uma introdução teórica e conceitual. In: Silva TT. Identidade e Diferença: a perspectiva dos estudos culturais. Petrópolis: Editora Vozes; 2011.

18. Louro GL. Um Corpo Estranho: Ensaios sobre sexualidade e teoria queer. Belo Horizonte: Autêntica Editora; 2008.

19. Ferrari A, Almeida MA, Dinali W. Teorias e subjetividades: Poder, Resistência e Corpo. In: Clareto SM, Ferrari A, organizadores. Foucault, Deleuze e Educação. Juiz de Fora: Editora UFJF; 2010.

20. Foucault M. Ditos e Escritos Ética, Sexualidade, Política Vol.5. Rio de Janeiro: Forense Universitária; 2006.

21. Vaz PRG. Um pensamento Infame: história e liberdade em Michel Foucault. Rio de Janeiro: Imago Editora; 1992.

22. Foucault M. Ditos e Escritos- Arte, Epistemologia Filosofia e História da Medicina Vol.VII. Rio de Janeiro: Forense Universitária; 2011.

23. Foucault M. Vigiar e Punir: Nascimento da prisão. Petrópolis: Editora Vozes; 2010.

24. Torres MA. A Diversidade Sexual na Educação e os Direitos LGBT na Escola. Belo Horizonte: Autêntica Editora; 2010.

25. Britzman D. Curiosidade, Sexualidade e Currículo. In: Louro GL. O Corpo Educado: Pedagogias da Sexualidade. Belo Horizonte:Autêntica Editora; 2010.

26. Heuser EMD.No Rastro da Filosofia da Diferença: In: Skliar C. Derrida e a Educação. Belo Horizonte: Autêntica; 2005.

27. Furlani J. Mulheres só fazem Amor com Homens? A educação sexual e os relacionamentos entre pessoas do mesmo sexo. Pró-Posições 2008; 19(2):111-131.

28. Ferrai A. Sujeitos, Subjetividades e Educação. Juiz de Fora: Editora UFJF; 2010.

Artigo apresentado em 20/03/2013

Aprovado em 30/04/2013

Versão final apresentada em 06/05/2013 